\title{
Electrochemical Studies on the Corrosion Behaviour of Reinforcing Steel in the Presence of Cyanoacetamide Derivatives as Corrosion Inhibitors
}

\author{
W. M. Yousef ${ }^{1,}{ }^{*}, Y$. Reda $^{2}$ and A. M.Eldesoky ${ }^{3}$ \\ ${ }^{1}$ Chemistry Department, Faculty of Science, Hail University/ Hail, P. O.Box 2440, Kingdom of Saudi \\ Arabia. \\ ${ }^{2}$ Chemical Engineering Department, High Institute of Engineering \&Technology (New Damietta), \\ Egypt. \\ ${ }^{3}$ Engineering_Chemistry Department, High Institute of Engineering \&Technology (New Damietta), \\ Egypt and Al-Qunfudah Center for Scientific Research (QCSR), Chemistry Department, Al- \\ Qunfudah University College, Umm Al-Qura University, KSA. \\ *E-mail: wafaa_youssef95@ hotmail.com
}

doi: $1020964 / 2018.12 .71$

Received: 24 October 2017 / Accepted: 20 October 2018 / Published: 5 November 2018

Using techniques such as Tafel polarization, (EIS) electrochemical impedance spectroscopy and (EFM) electrochemical frequency modulation, this work explored reinforcing steel corrosion and its inhibition by cyanoacetamide derivatives in $2 \mathrm{M} \mathrm{HCl}$ solutions. As indicated by the electrochemical analysis, a reduced corrosion rate and corrosion current density as well as more positive corrosion potential values were obtained by adding and increasing the concentration of the cyanoacetamide derivatives. The orders of the inhibition efficiency $(\% \eta)$ of Cyanoacetamide derivatives are given: (1) $>(2)>(3)$. Molecular docking was used to predict the binding between Cyanoacetamide derivatives with the receptor of 3tt8-hormone of crystal structure analysis of $\mathrm{Cu}$ Human Insulin Derivative.

Keywords: Reinforcing Steel, Cyanoacetamide, EIS, EFM, , Molecular docking

\section{$\underline{\text { FULL TEXT }}$}

(C) 2018 The Authors. Published by ESG (www.electrochemsci.org). This article is an open access article distributed under the terms and conditions of the Creative Commons Attribution license (http://creativecommons.org/licenses/by/4.0/). 